\title{
Color Stability of Different Denture Teeth Materials against Various Staining Agents
}

\author{
Temel KOKSAL and Idil DİKBAS \\ Department of Prosthodontics, Faculty of Dentistry, Yeditepe University, Istanbul, Turkey \\ Corresponding author, Temel KOKSAL; E-mail: temel_koksal@yahoo.com
}

Received December 20, 2006/Accepted August 21, 2007

The purpose of this in vitro study was to evaluate the color stability of two brands of porcelain teeth and three brands of acrylic denture teeth. Samples were immersed into three staining drinks as test groups and distilled water as a control. Color measurements of teeth were performed by using a spectrophotometer. Before immersion, the initial color value of each tooth was recorded. Color change values were determined after 1 day, 1 week, 2 weeks, and 4 weeks of immersion. Color differences were characterized using the CIE $\mathrm{L}^{*} \mathrm{a}^{*} \mathrm{~b}^{*}$ color space. The color stability of all teeth was significantly affected by the immersion period $(\mathrm{p}<0.0001)$. Instant coffee was found to be the most chromogenic agent among the solutions tested $(\mathrm{p}<0.0001)$. Among the materials tested, porcelain was found to be more resistant to discoloration. It was concluded that acrylic teeth showed a higher degree of color change and that the amount of color change for each group increased proportionally with time.

Keywords: Color stability, Spectrophotometer, Denture teeth

\section{INTRODUCTION}

In removable dentures, artificial teeth are a significant part of the overall esthetical outcome. In the maintenance of esthetical effects, the color stability of artificial tooth materials is one major factor. In this light, denture teeth are made of either methacrylate-based resins or ceramics. In particular, resin teeth are known to have sidelined ceramic teeth from the market recently. This is because resin teeth gain an upper hand over ceramic teeth by virtue of these advantageous properties: better bond to the denture base, lighter weight, and lower fracture proneness ${ }^{11}$. On the downside, conventional acrylic teeth are inferior to porcelain teeth in maintaining an adequate esthetic appearance with wear and discoloration, and thus have a shorter durability period and service life. To overcome the wear problems of conventional plastic teeth, high-strength plastic teeth have since been developed and applied clinically ${ }^{2}$.

Since high-strength plastic teeth made of hard resin are still susceptible to staining with pigments, it has been observed that the esthetics of removable partial dentures made from such plastic teeth is gradually impaired in many patients ${ }^{2}$. On the other hand, porcelain teeth are comparatively superior because of their high wear resistance and good esthetical appearance. However, if removable dentures were used for a long period of time without sufficient cleaning, there belies too the staining possibility of porcelain teeth because of the adsorption of colorants on the porcelain surface.

In dental literature, only a few studies have reported on the color stability of both acrylic and porcelain denture tooth materials ${ }^{3-5)}$. Against this backdrop of information scarcity, this in vitro study was undertaken to analyze the color changes of porcelain and acrylic denture teeth when exposed to common beverages by means of a spectrophotometer.

\section{MATERIALS AND METHODS}

In this study, two brands of porcelain teeth and three brands of reinforced acrylic teeth were used. The trade names, manufacturers, types, shades, forms, and codes of the denture teeth used in this study are given in Table 1. From each brand of denture teeth, 40 maxillary right central incisors of shade A1, of the largest size, and with the flattest surface were used.

Denture teeth were immersed into three staining solutions (instant coffee, tea, coke) and distilled water as detailed in Table 2 .

\section{Preparation of staining solutions}

The tea solution was prepared by immersing five teabags (Lipton Yellow Label Tea, Unilever, Istanbul, Turkey) into $1000 \mathrm{ml}$ of boiled water. To prepare the coffee solution, $20 \mathrm{~g}$ of coffee (Nescafe Classic, Nestle, Istanbul, Turkey) was poured into $1000 \mathrm{ml}$ of boiled distilled water. Both solutions were stirred every 30 minutes for 10 seconds until they cooled down to $37^{\circ} \mathrm{C}$, and then filtered through a filter paper. The third staining solution was coke (Coca-Cola, CocaCola Co., Turkey), whereby $1000 \mathrm{ml}$ of coke at room temperature was poured into a dish. Distilled water, as the fourth solution, was used as a control group.

Before pouring the solutions into dishes, 10 incisors from each brand labeled with a waterproof pen, were fixed vertically on the floor of a container to avoid tooth-to-tooth contact. Fixation was done using a removable adhesive (Tack-It, Faber-Castell, Nürnberg, Germany) at the cervical region of each tooth.

After both tea and coffee solutions cooled down 
Table 1 Denture teeth used in this study

\begin{tabular}{lllll}
\hline TYPE OF MATERIALS & TRADE NAME & CODE & MANUFACTURER & SHADE/FORM \\
\hline Reinforced acrylic & SR-VIVODENT DCL & SRVD & IVOCLAR-Liechtenstein & $010 /$ A17 \\
& VITAPAN & V & VITA Zahnfabrik-Germany & A1/098 \\
& OPTOSTAR & O & HERAEUS KULZER-Germany & A1/520 \\
\hline Porcelain & VIVOPERL PE & VP & IVOCLAR-Liechtenstein & $1 \mathrm{~A} / \mathrm{A} 17$ \\
& VIA LUMIN VACUUM & VLV & VTTA Zahnfabrik-Germany & A1/854 \\
\hline
\end{tabular}

Table 2 Solutions used in this study

\begin{tabular}{lll}
\hline $\begin{array}{l}\text { TYPE OF } \\
\text { SOLUTION }\end{array}$ & TRADE NAME & MANUFACTURER \\
\hline Tea & $\begin{array}{l}\text { Lipton Yellow } \\
\text { Label Tea }\end{array}$ & Unilever-Turkey \\
Instant cafe & Nescafe Classic & Nestle-Turkey \\
Coke & Coca-Cola & $\begin{array}{l}\text { Coca-Cola } \\
\text { Company-Turkey }\end{array}$ \\
Distilled Water & $-\cdots-------$ & $\begin{array}{l}\text { Yeditepe University, } \\
\text { Faculty of Dentistry- } \\
\end{array}$ \\
& & Turkey \\
\hline
\end{tabular}

to $37^{\circ} \mathrm{C}$, all solutions were poured into dishes and kept in an incubator. Solutions were freshened once every three days. In addition, to reduce the precipitation of particles in solutions, solutions were stirred once a day.

\section{Color measurements}

The specimens were placed in the center of the measuring head of a spectrophotometer with the aid of a silicone putty jig. This silicone mold was prepared so that repetitive measurements for each tooth could be taken from the same tooth region. Furthermore, this mold enabled all teeth from the same brand to sit on the measuring head of the spectrophotometer in the same position. Additionally, this setup prevented any external light source from entering the system. During the processing of the mold, teeth were placed so that their labial surfaces were at the same level as that of the silicone.

Before immersing each set of denture teeth into the solutions, they were stored in distilled water at $37 \pm 1^{\circ} \mathrm{C}$ for 24 hours. After 24 hours of immersion, the color measurement of each tooth $\left(\mathrm{T}_{0}\right)$ was performed using a spectrophotometer (CM-2600d, Konica Minolta Sensing Inc., Japan). After the first measurement $\left(\mathrm{T}_{0}\right)$, teeth were placed in containers as mentioned above. Subsequent color measurements were taken after 1 day $\left(\mathrm{T}_{1}\right), 1$ week $\left(\mathrm{T}_{2}\right), 2$ weeks $\left(\mathrm{T}_{3}\right)$, and 4 weeks $\left(\mathrm{T}_{4}\right)$ of immersion in solutions.

Before each measurement, teeth were removed
Table 3 National Bureau of Standards (NBS) ratings

\begin{tabular}{lll}
\hline NBC unit & \multicolumn{2}{l}{ Critical remarks of color differences } \\
$0.0-0.5$ & Trace: & Extremely slight change \\
$0.5-1.5$ & Slight: & Slight change \\
$1.5-3.0$ & Noticeable: & Perceivable change \\
$3.0-6.0$ & Appreciable: & Marked change \\
$6.0-12.0$ & Much: & Extremely marked change \\
12.0 or more & Very much: & Change to other color \\
\hline
\end{tabular}

from the solutions and rinsed in distilled water. Excess water on the surfaces was removed with tissue papers and teeth were allowed to dry.

Prior to measurement taking, the spectrophotometer was calibrated according to the manufacturer's instructions by using the supplied white calibration standard. Three measurements were taken at a time from one point which corresponded to the central region of the labial surface of each tooth. Average value of these three readings was automatically calculated by the spectrophotometer and recorded. Color changes were characterized using the Commission Internationale d'Eclairage $L^{*} a^{*} b^{*}$ color space (CIE L*a*b*).

The color systems are quantitative systems with rectangular coordinates, and they have a meaningful relation to the visual perception of color differences. Total color differences are expressed by the formula ${ }^{5}$, $\Delta \mathrm{E}^{*}=\left[(\Delta \mathrm{L})^{2}+(\Delta \mathrm{a})^{2}+(\Delta \mathrm{b})^{2}\right]^{1 / 2}$, where $\Delta \mathrm{L}, \Delta \mathrm{a}$, and $\Delta \mathrm{b}$ are differences in $\mathrm{L}^{*}, \mathrm{a}^{*}$, and $\mathrm{b}^{*}$ values before $\left(\mathrm{T}_{0}\right)$ and after immersion at each time interval $\left(\mathrm{T}_{1}\right.$, $\mathrm{T}_{2}, \mathrm{~T}_{3}, \mathrm{~T}_{4}$ ).

To relate the amount of color change $\left(\Delta \mathrm{E}^{*}\right)$ recorded by the spectrophotometer to a clinical environment, the data were converted to National Bureau of Standards units (NBS units) through the equation, NBS units $=\Delta \mathrm{E}^{*} \times 0.92$, where critical remarks of color differences as expressed in terms of NBS units. These values are shown in Table $3^{6}$. 


\section{Statistical analysis}

Discoloration results were analyzed by repeated measures analysis of variance (ANOVA), with two between-unit factors (five materials and four solutions) and one within-unit factor (four measurement times) to verify the main effects and possible interactions between factors. Two-way ANOVA at each immersion time was used to test the significance of factors involved. Where significant differences were found, one-way ANOVA and Newman-Keulls and Tukey's multiple comparison tests were applied to each between-unit factor.

\section{RESULTS}

Table 4 shows the total color difference $\left(\Delta \mathrm{E}^{*}\right)$ and corresponding NBS values of the denture teeth after 1 day, 1 week, 2 weeks and 4 weeks of immersion in all the test solutions. Statistical analysis results for the comparison of mean $\Delta \mathrm{E}^{*}$ values against different variables are shown in Tables 5, 6, and 7 .

Results of repeated measures ANOVA indicated that all factors (time, denture teeth, and solution) and all their possible interactions were statistically significant. Two-way ANOVA revealed that the color stability of all teeth was significantly affected by the immersion period $(\mathrm{p}<0.0001)$. Another result of twoway ANOVA revealed that the porcelain material (VL and VLV) was more resistant to discoloration than the resin material (SRVD, V, and O).

When NBS values were evaluated, instant coffee solution was observed to cause "perceivable" color difference at the end of fourth week for only acrylic teeth groups. The staining effects of the other solutions resulted in only slight color changes that could not be noticed by naked eye. Further, it was shown that the color changes of denture teeth intensified with increasing immersion period (Table 4).

In Table 5 where the color changes of denture teeth at the end of each immersion period were compared, there were no significant differences between the $\Delta \mathrm{E}^{*}$ values within each teeth group when immersed in tea and coffee solutions.

For the immersion of porcelain teeth in tea and coffee, there were no statistically significant differences between the $\Delta \mathrm{E}^{*}$ values for these two solu-

Table 4 Color differences of denture teeth

\begin{tabular}{|c|c|c|c|c|c|c|c|c|c|c|c|c|c|}
\hline \multirow[t]{2}{*}{ Teeth } & \multirow[t]{2}{*}{ Periods } & \multicolumn{3}{|c|}{ Distiled water } & \multicolumn{3}{|c|}{ Tea } & \multicolumn{3}{|c|}{ Coffee } & \multicolumn{3}{|c|}{ Coke } \\
\hline & & $\begin{array}{l}\Delta \mathrm{E}^{*} \\
\text { (mean) }\end{array}$ & $\mathrm{SD}$ & $\begin{array}{l}\text { NBC } \\
\text { unit }\end{array}$ & $\begin{array}{l}\Delta \mathrm{E}^{*} \\
\text { (mean) }\end{array}$ & $\mathrm{SD}$ & $\begin{array}{l}\text { NBC } \\
\text { unit }\end{array}$ & $\begin{array}{l}\Delta \mathrm{E}^{*} \\
\text { (mean) }\end{array}$ & SD & $\begin{array}{l}\text { NBC } \\
\text { unit }\end{array}$ & $\begin{array}{l}\Delta \mathrm{E}^{*} \\
\text { (mean) }\end{array}$ & SD & $\begin{array}{l}\text { NBC } \\
\text { unit }\end{array}$ \\
\hline \multirow{4}{*}{ SRVD } & $1 d$ & 0.185 & 0.12 & 0.170 & 0.718 & 0.33 & 0.661 & 0.965 & 0.40 & 0.888 & 0.403 & 0.27 & 0.371 \\
\hline & $1 \mathrm{w}$ & 0.248 & 0.13 & 0.228 & 0.976 & 0.30 & 0.898 & 1.829 & 0.36 & 1.683 & 0.648 & 0.33 & 0.596 \\
\hline & $2 \mathrm{w}$ & 0.188 & 0.08 & 0.173 & 1.051 & 0.28 & 0.967 & 2.274 & 0.81 & 2.092 & 0.765 & 0.38 & 0.704 \\
\hline & $4 \mathrm{w}$ & 0.275 & 0.15 & 0.253 & 1.273 & 0.40 & 1.171 & 2.828 & 1.03 & 2.602 & 0.894 & 0.41 & 0.822 \\
\hline \multirow{4}{*}{$\mathrm{V}$} & $1 d$ & 0.849 & 0.69 & 0.781 & 0.654 & 0.10 & 0.602 & 0.741 & 0.15 & 0.682 & 0.522 & 0.15 & 0.480 \\
\hline & $1 \mathrm{w}$ & 0.589 & 0.21 & 0.542 & 0.824 & 0.17 & 0.758 & 1.102 & 0.25 & 1.014 & 0.676 & 0.34 & 0.622 \\
\hline & $2 \mathrm{w}$ & 0.469 & 0.24 & 0.431 & 1.081 & 0.34 & 0.995 & 1.334 & 1.02 & 1.227 & 0.708 & 0.16 & 0.651 \\
\hline & $4 \mathrm{w}$ & 0.368 & 0.22 & 0.339 & 1.161 & 0.26 & 1.068 & 1.859 & 1.08 & 1.710 & 0.817 & 0.36 & 0.752 \\
\hline \multirow{4}{*}{$\mathrm{O}$} & $1 d$ & 0.546 & 0.14 & 0.502 & 0.529 & 0.10 & 0.487 & 0.706 & 0.15 & 0.650 & 0.409 & 0.28 & 0.376 \\
\hline & $1 \mathrm{w}$ & 0.260 & 0.16 & 0.239 & 0.593 & 0.15 & 0.546 & 1.325 & 0.16 & 1.219 & 0.497 & 0.27 & 0.457 \\
\hline & $2 \mathrm{w}$ & 0.491 & 0.30 & 0.452 & 0.676 & 0.24 & 0.622 & 1.476 & 0.24 & 1.358 & 0.547 & 0.18 & 0.503 \\
\hline & $4 \mathrm{w}$ & 0.538 & 0.33 & 0.495 & 0.960 & 0.11 & 0.883 & 2.150 & 0.38 & 1.978 & 0.681 & 0.20 & 0.627 \\
\hline \multirow{4}{*}{ VP } & $1 d$ & 0.240 & 0.12 & 0.221 & 0.380 & 0.29 & 0.350 & 0.365 & 0.17 & 0.336 & 0.261 & 0.18 & 0.240 \\
\hline & $1 \mathrm{w}$ & 0.257 & 0.12 & 0.236 & 0.397 & 0.31 & 0.365 & 0.523 & 0.10 & 0.481 & 0.584 & 0.13 & 0.537 \\
\hline & $2 \mathrm{w}$ & 0.205 & 0.11 & 0.189 & 0.453 & 0.36 & 0.417 & 0.879 & 0.75 & 0.809 & 0.855 & 0.42 & 0.787 \\
\hline & $4 \mathrm{w}$ & 0.233 & 0.10 & 0.214 & 0.579 & 0.37 & 0.533 & 1.009 & 0.36 & 0.928 & 0.829 & 0.61 & 0.763 \\
\hline \multirow{4}{*}{ VLV } & $1 d$ & 0.267 & 0.17 & 0.246 & 0.517 & 0.11 & 0.476 & 0.398 & 0.06 & 0.366 & 0.715 & 0.26 & 0.658 \\
\hline & $1 \mathrm{w}$ & 0.292 & 0.14 & 0.269 & 0.589 & 0.20 & 0.542 & 0.615 & 0.12 & 0.566 & 0.808 & 0.31 & 0.743 \\
\hline & $2 \mathrm{w}$ & 0.299 & 0.06 & 0.275 & 0.699 & 0.25 & 0.643 & 0.736 & 0.29 & 0.677 & 0.795 & 0.24 & 0.731 \\
\hline & $4 w$ & 0.319 & 0.19 & 0.293 & 0.750 & 0.35 & 0.690 & 0.832 & 0.26 & 0.765 & 0.924 & 0.29 & 0.850 \\
\hline
\end{tabular}

$\Delta \mathrm{E}^{*}$ : Color change value; SD: Stnadard Deviation; NBS unit: National Bureau of Standards unit 
Table 5 Comparison of the mean $\Delta \mathrm{E}^{*}$ values of denture tooth materials against different solutions for each immersion period

\begin{tabular}{|c|c|c|c|c|c|}
\hline Teeth & Periods & $\begin{array}{l}\text { Distiled } \\
\text { water }\end{array}$ & Tea & Coffee & Coke \\
\hline \multirow{4}{*}{ SRVD } & $1 d$ & $\mathrm{~A}$ & $\mathrm{BC}$ & B & $\mathrm{AC}$ \\
\hline & $1 \mathrm{w}$ & $\mathrm{D}$ & $\mathrm{E}$ & $\mathrm{F}$ & $\mathrm{E}$ \\
\hline & $2 \mathrm{w}$ & $\mathrm{G}$ & $\mathrm{H}$ & I & $\mathrm{H}$ \\
\hline & $4 \mathrm{w}$ & J & $\mathrm{KM}$ & $\mathrm{L}$ & M \\
\hline \multirow{4}{*}{ V } & $1 d$ & $\mathrm{~N}$ & $\mathrm{~N}$ & $\mathrm{~N}$ & $\mathrm{~N}$ \\
\hline & $1 \mathrm{w}$ & $\mathrm{O}$ & $\mathrm{OP}$ & $\mathrm{P}$ & $\mathrm{O}$ \\
\hline & $2 \mathrm{w}$ & $\mathrm{P}$ & $\mathrm{QR}$ & $\mathrm{R}$ & $\mathrm{PQ}$ \\
\hline & $4 \mathrm{w}$ & $\mathrm{S}$ & $\mathrm{T}$ & $\mathrm{U}$ & VT \\
\hline \multirow{4}{*}{$\mathrm{O}$} & $1 d$ & WX & WX & W & $\mathrm{X}$ \\
\hline & $1 \mathrm{w}$ & $\mathrm{Y}$ & $\mathrm{Z}$ & $\Omega$ & $\mathrm{Z}$ \\
\hline & $2 \mathrm{w}$ & $\alpha$ & $\alpha$ & $\beta$ & $\alpha$ \\
\hline & $4 \mathrm{w}$ & $\gamma$ & $\zeta$ & $\Gamma$ & $\gamma \zeta$ \\
\hline \multirow{4}{*}{ VP } & $1 d$ & $\varepsilon$ & $\varepsilon$ & $\varepsilon$ & $\varepsilon$ \\
\hline & $1 w$ & $\Delta$ & $\Delta \eta$ & $\eta$ & $\eta$ \\
\hline & $2 \mathrm{w}$ & $\theta$ & $\theta \lambda \mu$ & $\lambda \rho$ & $\mu \rho$ \\
\hline & $4 w$ & $\nu$ & $\nu \pi$ & $\sigma \tau$ & $\pi \tau$ \\
\hline \multirow{4}{*}{ VLV } & $1 d$ & $\phi$ & $\chi$ & $\phi \chi$ & $\Psi$ \\
\hline & $1 \mathrm{w}$ & $\omega$ & $\delta$ & $\delta$ & $\delta$ \\
\hline & $2 \mathrm{w}$ & $\ddot{i}$ & ó & ó & ó \\
\hline & $4 \mathrm{w}$ & Б & $E$ & E & E \\
\hline
\end{tabular}

Same letters or symbols in the same row indicate insignificant differences $(\mathrm{p}>0.05)$.

Table 6 Comparison of the mean $\Delta \mathrm{E}^{*}$ values of each denture tooth material with respect to different immersion periods

\begin{tabular}{|c|c|c|c|c|c|}
\hline Teeth & Periods & $\begin{array}{l}\text { Distiled } \\
\text { water }\end{array}$ & Tea & Coffee & Coke \\
\hline \multirow{4}{*}{ SRVD } & $1 d$ & $\mathrm{~A}$ & $\mathrm{~K}$ & $\gamma$ & Њ \\
\hline & $1 \mathrm{w}$ & A & $\mathrm{L}$ & $\theta \lambda$ & К Б \\
\hline & $2 \mathrm{w}$ & A & $\mathrm{M}$ & $\eta \lambda$ & ў $\mathrm{B}$ \\
\hline & $4 \mathrm{w}$ & A & $\mathrm{N}$ & $\Delta$ & $Џ$ \\
\hline \multirow{4}{*}{$\mathrm{V}$} & $1 d$ & $\mathrm{BD}$ & $\mathrm{O}$ & $\mu \rho$ & Д \\
\hline & $1 \mathrm{w}$ & B & $\mathrm{P}$ & $\nu \pi$ & Д И \\
\hline & $2 \mathrm{w}$ & $\mathrm{BD}$ & QS & $\rho \pi$ & Жи \\
\hline & $4 \mathrm{w}$ & $\mathrm{CD}$ & $\mathrm{RS}$ & $\nu \sigma$ & з И \\
\hline \multirow{4}{*}{$\mathrm{O}$} & $1 d$ & $\mathrm{E}$ & $\mathrm{U}$ & $\tau$ & $\Phi$ \\
\hline & $1 \mathrm{w}$ & $\mathrm{F}$ & UV & $\phi$ & $\Phi Ч$ \\
\hline & $2 \mathrm{w}$ & $\mathrm{EF}$ & UY & $\chi$ & $\Phi \amalg$ \\
\hline & $4 w$ & $\mathrm{E}$ & Z & $\Psi$ & Б \\
\hline \multirow{4}{*}{ VP } & $1 d$ & I & $\alpha$ & $\omega \ddot{\mathrm{E}}$ & $\ni$ \\
\hline & $1 \mathrm{w}$ & I & $\alpha$ & $\ddot{i}$ & Юə \\
\hline & $2 \mathrm{w}$ & I & $\alpha$ & ïóЁ & $¥ ə$ \\
\hline & $4 \mathrm{w}$ & I & $\alpha$ & üó & Чә \\
\hline \multirow{4}{*}{ VLV } & $1 d$ & $\mathrm{~J}$ & $\beta$ & Б & $\theta$ \\
\hline & $1 \mathrm{w}$ & $\mathrm{J}$ & $\beta$ & $\dot{\Gamma}$ & $\theta$ \\
\hline & $2 \mathrm{w}$ & $\mathrm{J}$ & $\beta$ & గ́ $€$ & $\theta$ \\
\hline & $4 \mathrm{w}$ & $\mathrm{J}$ & $\beta$ & ЃगБ & $\theta$ \\
\hline
\end{tabular}

Same letters or symbols in the same column for each teeth group indicate insignificant differences $(p>0.05)$.
Table 7 Comparison of the mean $\Delta \mathrm{E}^{*}$ values of denture tooth materials in the same immersion period

\begin{tabular}{|c|c|c|c|c|c|}
\hline Periods & Teeth & $\begin{array}{l}\text { Distiled } \\
\text { water }\end{array}$ & Tea & Coffee & Coke \\
\hline \multirow{5}{*}{$1 d$} & SRVD & $\mathrm{A}$ & $\mathrm{L}$ & $\mathrm{X}$ & K \\
\hline & $\mathrm{V}$ & B & LM & $\mathrm{X}$ & к $\mu$ \\
\hline & $\mathrm{O}$ & $\mathrm{AB}$ & LM & $\mathrm{X}$ & к \\
\hline & $\mathrm{VP}$ & $\mathrm{AC}$ & $\mathrm{M}$ & $\mathrm{Y}$ & к \\
\hline & VLV & $\mathrm{AD}$ & $\mathrm{LM}$ & $\mathrm{Y}$ & $\mu$ \\
\hline \multirow{5}{*}{$1 \mathrm{w}$} & SRVD & $\mathrm{E}$ & $\mathrm{N}$ & $\mathrm{Z}$ & $\pi$ \\
\hline & $\mathrm{V}$ & $\mathrm{F}$ & NOR & $\alpha$ & $\pi$ \\
\hline & $\mathrm{O}$ & $\mathrm{E}$ & $\mathrm{OP}$ & $\alpha$ & $\pi$ \\
\hline & VP & $\mathrm{E}$ & $\mathrm{P}$ & $\beta \gamma$ & $\pi$ \\
\hline & VLV & $\mathrm{E}$ & $\mathrm{RP}$ & $\gamma$ & $\pi$ \\
\hline \multirow{5}{*}{$2 \mathrm{w}$} & SRVD & G & QS & $\zeta$ & $\Phi$ \\
\hline & $\mathrm{V}$ & $\mathrm{H}$ & $\mathrm{Q}$ & $\varepsilon$ & $\Phi$ \\
\hline & $\mathrm{O}$ & IH & $\mathrm{ST}$ & $\zeta \varepsilon$ & $\Phi$ \\
\hline & $\mathrm{VP}$ & $\mathrm{G}$ & $\mathrm{T}$ & $\varepsilon$ & $\Phi$ \\
\hline & VLV & $\mathrm{GH}$ & $\mathrm{QT}$ & $\varepsilon$ & $\Phi$ \\
\hline \multirow{5}{*}{$4 w$} & SRVD & JK & $\mathrm{U}$ & $\Delta$ & $\Psi$ \\
\hline & V & JK & $\mathrm{U}$ & $\eta \theta$ & $\Psi$ \\
\hline & $\mathrm{O}$ & $\mathrm{J}$ & UV & $\Delta \eta$ & $\Psi$ \\
\hline & $\mathrm{VP}$ & $\mathrm{K}$ & $\mathrm{V}$ & $\Theta \lambda$ & $\Psi$ \\
\hline & VLV & J & $\mathrm{V}$ & $\lambda$ & $\Psi$ \\
\hline
\end{tabular}

Same letters or symbols in the same column indicate insignificant differences $(p>0.05)$ for each immersion period

tions after one day and one month of immersion. However; for all acrylic teeth groups, there were statistically significant differences between the mean $\Delta \mathrm{E}^{*}$ values after one day and one month of immersion in the three staining solutions (Table 6).

When comparison was made among the staining solutions, the instant coffee solution was found to be more chromogenic than the other solutions $(p<0.0001)$. For example, between tea and coke, there were no significant differences between these two solutions in their staining effects.

When comparison was made among the denture tooth materials, porcelain teeth exhibited higher color stability in tea and coffee solutions as compared to the acrylic ones. In the coke solution, no evident differences were observed between the porcelain and acrylic teeth (Table 7).

\section{DISCUSSION}

Color changes can be evaluated visually or by instrumental techniques. Since instrumental measurements eliminate the subjective interpretation of visual color comparison, spectrophotometers or colorimeters are used instead of visual evaluation ${ }^{7,8)}$.

Color changes were characterized using the Commission Internationale d'Eclairage $\mathrm{L}^{*} \mathrm{a} * \mathrm{~b} *$ color space (CIE L*a*b*). The CIE L*a*b* color 
space is currently one of the most popular and widely used color spaces and it is well suited for the determination of small color differences ${ }^{9}$. In this three-dimensional color space, the three axes are namely $L^{*}, a^{*}$, and $b^{*}$. The $L^{*}$ value is a measure of the whiteness or brightness of an object. The $a^{*}$ value is a measure of redness (positive $a^{*}$ ) or greenness (negative $a^{*}$ ). The $b^{*}$ value is a measure of yellowness (positive $b^{*}$ ) or blueness (negative $b^{*}$ ). The advantage of the CIE $L^{*} a * b *$ system is that color differences can be expressed in units that can be related to visual perception and clinical significance ${ }^{10)}$.

Color difference $\left(\Delta E^{*}\right)$ was calculated from a formula previously mentioned. In dental literature, many authors ${ }^{4,7,11-13)}$ used $\Delta \mathrm{E}^{*}$ values to evaluate the "perceptibility" of color differences. However, it is noteworthy that the criteria of perceptibility adopted by each author were different. To counter such differences and disagreements in the criteria used, the NBS rating system is a frequently used method to determine the degree of color difference since it offers absolute criteria by which $\Delta \mathrm{E}^{*}$ values can be converted to remarks with clinical significance ${ }^{6)}$. In the present study, therefore, corresponding NBS units were calculated to assess the color differences caused by immersion time and/or solution type. It was found that the NBS values of all acrylic teeth groups when immersed in instant coffee were greater than 1.5, meaning that color change was "noticeable (perceivable)" (Table 4).

Apart from color change in instant coffee, the $L^{*}, a^{*}$, and $b^{*}$ values of all teeth groups changed in relation to immersion period. In the assessment of $L^{*}$ values, it was determined that the teeth became darker with time. The $a^{*}$ values signified a shift toward green while the $b^{*}$ values a shift toward yellow.

It was pointed out that there is a correlation between color and discoloration in provisional restorative materials and dental composites, and was confirmed that lighter materials discolor more markedly than darker ones ${ }^{14,15,16)}$. On this ground, teeth of shade A1 were selected for this study because they supposedly exhibit the staining effect more distinctly. Nonetheless, the effect of staining solutions on darker teeth should be a subject to be further investigated in future studies.

For drinks, coffee, tea, and coke are identified to be staining substances ${ }^{3,7,9,17-20)}$. For this reason, these solutions were used in this study for staining effect evaluation. Among these three solutions, coffee was the most chromogenic agent. This finding was consistent with a study performed by Mutlu-Sagesen et $a l .{ }^{3)}$, which investigated the color stability of denture teeth. Besides, numerous studies ${ }^{18,19,21,22,23,24)}$ also concluded that coffee was more staining than tea.
In the present study, when acrylic denture teeth were compared against porcelain, it was found that the former group exhibited less color stability than the latter in all the three staining solutions (Table 4). This result was consistent with the studies of Satoh et al. ${ }^{2}$, Mutlu-Sagesen et al. ${ }^{3)}$, and Belli et al. ${ }^{25}$. This could be explained by the water sorption property of acrylic materials. Staining agents in tea, coffee, and cola penetrated into the acrylic materials because of this absorption property.

When NBS values at the fourth week immersion period were evaluated, "perceivable" changes were observed only in acrylic teeth groups immersed in instant coffee solution. Color changes in tea and coke solutions were only "slight changes" according to the NBS rating system. However, in another study ${ }^{23)}$ performed with a similar methodology which investigated the color changes of acrylic denture base materials, "perceivable" color changes were noted not only in coffee but also in tea solution at the end of fourth week. Differences on these two studies' results could be due to differences between the structures of denture base acrylic and reinforced acrylic of denture teeth.

A period of four weeks' immersion might be considered by some as too long an experimental period. However; in most in vitro studies ${ }^{2,3,7,13,26,27,28)}$, the final period is typically four weeks or more in order to achieve a cumulative staining effect and obtain distinct results. One of the drawbacks in the present investigation might be related with the methodology utilized for the staining procedure. Between the different immersion intervals, the experimental tooth specimens were not subjected to any cleaning procedure, which might not accurately reflect clinical conditions. Thus, the results obtained herein might serve to reveal the consequences of a low quality denture care.

Color differences with corresponding $\Delta \mathrm{E}^{*}$ values lower than 3.3 are acceptable in clinical dentistry ${ }^{7,15}$. In the current study, the $\Delta \mathrm{E}^{*}$ values of all groups did not exceed 3.3. Therefore, it was concluded that the staining of all teeth groups by the solutions used in this study remained in clinically acceptable ranges. A similar study ${ }^{23)}$ performed to investigate the color stability of three denture base materials showed that color changes for these materials in (the most staining) instant coffee solution for four weeks remained within clinically acceptable limits - with $\Delta \mathrm{E}^{*}$ values being less than 3.3. This result was consistent with the present study and could be considered as complementary findings because denture base materials are the other component of removable dentures.

\section{CONCLUSIONS}

Within the limitations of this in vitro study, the fol- 
lowing conclusions were drawn:

(1) Porcelain denture teeth were more color-stable than reinforced acrylic denture teeth.

(2) Discoloration of teeth increased proportionally with immersion period.

(3) The most chromogenic staining solution was found to be the instant coffee solution.

\section{REFERENCES}

1) Stober T, Lutz T, Gilde H, Rammelsberg P. Wear of resin denture teeth by two-body contact. Dent Mater 2006; 22: 243-249.

2) Satoh Y, Nagai E, Azaki M, Morikawa M, Ohyama T, Toyoma H, Itoh S, Sakurai H, Iwasawa A, Ohwa M, et al. Study on high-strength plastic teeth. Tooth discoloration. J Nihon Univ Sch Dent 1993; 35: 192-199.

3) Mutlu-Sagesen L, Ergun G, Ozkan Y, Bek B. Color stability of different denture teeth materials: an in vitro study. J Oral Sci 2001; 43: 193-205.

4) Liberman R, Combe EC, Piddock V, Watts DC. Color changes in acrylic teeth - comparison of an objective and subjective method. J Oral Rehabil 1996; 23: 464-469.

5) Rosentritt M, Esch J, Behr M, Leibrock A, Handel G. In vivo color stability of resin composite veneers and acrylic resin teeth in removable partial dentures. Quintessence Int 1998; 29: 517-522.

6) Razzoog ME, Lang BR, Russell MM, May KB. A comparison of the color stability of conventional and titanium dental porcelain. J Prosthet Dent 1994; 72: 453-456.

7) Um CM, Ruyter IE. Staining of resin-based veneering materials with coffee and tea. Quintessence Int 1991; 22: 377-386.

8) Buyukyılmaz S, Ruyter IE. Color stability of denture base polymers. Int J Prosthodont 1994; 7: 372 382 .

9) Khokhar ZA, Razzoog ME, Yaman P. Color stability of restorative resins. Quintessence Int 1991; 22: 733-737.

10) Joiner A. Tooth colour: a review of the literature. J Dent 2004; 32: 3-12.

11) Stober T, Gilde H, Lenz P. Color stability of highly filled composite resin materials for facings. Dent Mater 2001; 17: 87-94.

12) Seghi RR, Hewlett ER, Kim J. Visual and instrumental colorimetric assessments of small color differences on translusent dental porcelain. J Dent Res1989; 68: 1760-1764.

13) Yannikakis SA, Zissis AJ, Polyzois GL, Caroni C.
Color stability of provisional resin restorative materials. J Prosthet Dent 1998; 80: 533-539.

14) Eldiwany M, Friedl KH, Powers JM. Color stability of light-cured and post-cured composites. Am J Dent 1995; 8: 179-181.

15) Uchida H, Vaidyanathan J, Viswanadhan T, Vaidyanathan TK. Color stability of denture composites as a function of shade. J Prosthet Dent 1998; 79: 372-377.

16) Mutlu-Sagesen L, Ergun D, Ozkan Y, Semiz M. Color stability of dental composite after immersion in various media. Dent Mater J 2005; 24: 382-390.

17) Cooley RL, Barkmeier WW, Matis BA. Siok JF. Staining of posterior resin restorative materials. Quintessence Int 1987; 18: 823-827.

18) Luce MS, Camphell CE. Stain potential of four microfilled composites. J Prosthet Dent 1988; 60: 151-154.

19) Chan KC, Fuller JL, Hormati AA. The ability of foods to stain two composite resins. J Prosthet Dent 1980; 43: 542-545.

20) Polyzois GL, Yannikakis SA, Zissis AJ. Color stability of visible light-cured, hard direct denture reliners: an in vitro investigation. Int J Prosthodont 1999; 12: 140-146.

21) Chan KC, Hormati AA, Kerber PE. Staining calcified dental tissues with food. J Prosthet Dent 1981; 46: $175-178$.

22) Scotti R, Mascellani SC, Forniti F. The in vitro color stability of acrylic resins for provisional restorations. Int J Prosthodont 1997; 10: 164-168.

23) Koksal T, Dikbas I. Effect of various drinks on color stability of denture base materials. Academic Dental 2007; 9: 20-24.

24) Ertas E, Guler AU, Yucel AC, Koprulu H, Guler E. Color stability of resin composites after immersion in different drinks. Dent Mater J 2006; 25: 371-376.

25) Belli S, Tanruverdi FF, Belli E. Colour stability of three esthetic laminate materials against to different staining agents. J Marmara Univ Dent Fac 1997; 2: 643-648.

26) Inokoshi S, Burrow MF, Kataumi M, Yamada T, Takatsu T. Opacity and color changes of toothcolored restorative materials. Oper Dent 1996; 21: 73-80.

27) Fujita M, Kawakami S, Noda M, Sano H. Color change of newly developed esthetic restorative material immersed in food-simulating solutions. Dent Mater J 2006; 25: 352-359.

28) Omata Y, Uno S, Nakaoki Y, Tanaka T, Sano H, Yoshida S, Sidhu SK. Staining of hybrid composites with coffee, oolong tea, or red wine. Dent Mater J 2006; 25 : 125-131. 